\title{
Clinical Characteristics And Analysis Of Risk Factors For Disease Progression Of COVID-19 Among Patients Within Wad Medani Isolation Centers, Gezira State: A Retrospective Cohort Study From Sudan
}

Mohammed Yousif Elnaeem Yousif

Moh.Mah.Fadel Allah Eljack

Osman Amir

Mohammed Alfatih

Akram Khalid Al Tigany Al Shiekh

Mazin Abdelraham Osman Ahmed

Alshareef Nour

Mazin S. Haroun

Khabab Abbasher Hussien Mohamed Ahmed ( $\sim$ Khabab9722@gmail.com )

University of Khartoum, Faculty of Medicine https://orcid.org/0000-0003-4608-5321

Radi Tofaha Alhusseini

Waddah Aljaely Mohammed Osman

Mohamed Abdulkarim

Mohammed Eltahier Abdalla Omer

Research Article

Keywords: COVID-19, Clinical characteristics, Risk factors, Sudan

Posted Date: October 13th, 2021

DOI: https://doi.org/10.21203/rs.3.rs-967313/v1

License: (c) (i) This work is licensed under a Creative Commons Attribution 4.0 International License.

Read Full License 


\section{Abstract \\ Background :}

(COVID-19) had a great impact on the world's health systems since December 2019. A little is known about the clinical characteristics and risk factors associated with COVID-19 severity in Sudanese Patients; therefor it is necessary to summarize the clinical characteristics of patients with COVID-19 and to explore the risk factors associated with COVID-19 severity.

\section{Methods :}

A one-year retrospective cohort study (May 2020-May2021) was done at three isolation centers in Wad Medani. Sample contained all COVID-19 patients who are over 18 years old and were confirmed to be COVID-19 by nucleic acid testing or features Suggestive of Covid19 on Chest CT scan.

\section{Results :}

This study included 418 patients confirmed COVID-19 cases with a median age of $66.3 \pm 13$ years. 179 (64.2\%) patients were men. Hypertension $(n=195 ; 46.7 \%)$ and diabetes $(n=187 ; 44.7 \%)$ were the most common comorbidities. The most common symptoms at COVID-19 onset were fever $(n=303 ; 72.5 \%)$, cough $(n=278 ; 66.5 \%)$ and dyspnea $(n=256 ; 61.2 \%)$. the overall mortality rate was $35.4 \%(n=148)$. The morality rate was $42.3 \%(n=118)$ among patients with severe disease. The Chi-square test and ANOVA analysis revealed that older age, anemia, neutrophilia and lymphcytopenia, higher glucose levels, HbA1c levels and creatinine levels were variables associated with severe COVID-19. In inflammatory markers, the levels of CRP and d-dimer were elevated in severe infection more than moderate and mild infections.

\section{Conclusion :}

Patients with these factors are more likely to deteriorate into severe infection and have higher mortality rate than those without these factors.

\section{Introduction}

After the first case of coronavirus disease (COVID-19) in Wuhan, China since December 2019, the severe acute respiratory syndrome coronavirus 2 (SARS-CoV-2) has spread to over 200 countries in about 3 months. On March 11, 2020, the WHO emergency committee declared it a global health emergency, more than 200 countries have reported coronavirus disease 2019 (COVID-19) (1-3).

Global pandemic caused a great impact on the world's health systems and is causing a lot of deaths and affecting the world in many aspects, economically and socially and its rapid spread around the globe. 
Since first case of COVID-19 reported in Sudan on 13 March 2020 there are more than 38,000 cases in Sudan confirmed with 2,833 deaths and 31,590 recovered cases also more than 8 million case in Africa and more than 226 million cases around the globe until the 17 September $2021(4,5)$.

From 13th March 2020, and up to 11 November 2020 according to study done to summarize the COVID19 situation in Sudan; indicating a relatively high case fatality rate of $7.7 \%$. Also several preventive and control measures were implemented by the government of Sudan and health partners including the partial lockdown, social distancing, etc. However, new cases still emerging every day and the highest numbers of cases were in Khartoum State then Gezira state. Regarding the total number of the death per the state; Khartoum state has the highest number of total deaths followed by Gezira state this is because of the proportionally high number of cases reported from Khartoum state to other states of the country. Khartoum state has reported lower fatality rates in Sudan while other states reported extremely high case fatality rate, highlights the relatively better case management in the capital city, Khartoum, and further underscores the centralization of healthcare system in the country (6).

Up to now, most studies have focused on the prevention and treatment of severe patients, which may develop into respiratory failure or even death (7).

Most studies to date have investigated risk factors associated with the severity of COVID-19. Older patients, male gender, patients had diabetes mellitus, chronic kidney disease, and CVD rate in comorbidities, previous history of pneumonia, dyspnea, headache and neurological symptoms, increase respiratory rates and pulse rate, anemia, malaria infection, neutrophilia, lymphcytopenia, higher glucose levels, HbA1c levels and creatinine levels, increase levels of CRP and d-dimer were associated with increased risks of severe COVID-19 and increase the risk of death from COVID-19 (8-10). However, little is known about the clinical characteristics and risk factors for disease progression of COVID-19 in Sudanese Patients. Therefore it is necessary to summarize and analyze the clinical, laboratory and imaging characteristics of patients diagnosed with COVID-19, and to describe the potential risk factors for disease progression. Our aim was to describe the clinical characteristics of patients with COVID-19 and to explore the risk factors associated with COVID-19 severity in Wad Medani Isolation Centers in Gezira state, Sudan.

\section{Methodology}

\section{Study design:}

This is a retrospective cohort which was done between May 2020 to May 2021 in two Isolation Centers Wad Medani in Gezira state, Sudan.

\section{Study area:}

The study took place in Wad Medani ,the capital of Gezira state which is second largest state in Sudan with total number of population $4,133,048$, which composed of 32 secondary and Tertiary hospital 
receive patients from Gezira, Sinnar, Blue Nile, Kassala, Al_Gadarif and white Nile states. Two isolation centers involved in the study, the first composed of 65 beds for mild to moderate cases, while the second is for critical cases with capacity of 10 icu beds supplemented with 10 mechanical ventilators and 2 hemodialysis machines.

The total number of cases admitted is 4300 suspected case 2214 of them results back positive for COVID19 admitted to the center, 1727 underwent full recovery and 481 patients passed Away.

\section{Data collection:}

A well-structural questionnaire was used to collect data which composed of eight sections entitled personal data, comorbidities, symptoms, signs, laboratory investigations and radiological findings, clinical course, outcome and duration of illness.

\section{Study population:}

The target population of this study are patients with COVID-19 of both genders, who admitted to Wad Medani isolation centers, Gezira state, Sudan from May 2020-May 2021 and they were 418 patients.

Inclusion criteria:

1/Adults over 18 years

2/All patients were confirmed to be covid_19 by nucleic acid testing or features suggestive of covid_19 on chest CT Scan

3/Patients who have complete medical record

Exclusion criteria:

1/ Patients outside the study period and area

2/Patients who haven't been confirmed by nucleic acid or CT chest

3/Patients with incomplete clinical data

4/Patients sent firstly for home isolation and then admitted to isolaton centers

\section{Data collection tool and technique:}

Data from medical records was reviewed and collected by professional doctors. All data was collected from all patients' medical records include:

- Socio-demographics:

Age and Gender 
- Comorbidities:

HTN, CVD, cerebrovascular, Cancer, DM, Chronic Kidney Disease and Chronic Pulmonary Disease, Autoimmune Diseases, Others (Thyroid, Prostate, Gynecological...etc.)

- Symptoms and signs of COVID-19 and initial laboratory findings (hematological, blood chemical, coagulation and infection related tests)

- . Diagnostic Tools(Nasal Swab, CT Chest, Chest X-Ray)

- Disease duration and clinical outcome

\section{Sample size and sampling technique:}

The clinical data was obtained from all COVID-19 patients medical record, who were admitted to the Wad Medani Isolation Centers in the period between May 2020 to May 2021 and who meet the criteria to be including in the study.

\section{Statistical Analysis Plan:}

Data from medical records was collected using a data collection sheet (Appendix 1) by the researchers. Statistical analysis was performed using the Statistical Package for Social Science (SPSS, Version 24). The Chi-square test and ANOVA test were used to evaluate the association of interested variables and results were expressed as tables and figure.

\section{Ethical approval and Consent:}

Ethical approval was obtained from each center ethical committee. Both written and verbal consents were obtained from each patient.

\section{Results}

All 418 patients included in this study were admitted to Wad-Madani Isolation Center, 279 (66.7\%) patients were men and $139(33.3 \%$ ) were women, their mean age was $66.3 \pm 13 y e a r s$ (table 1 ). according to COVID-19 severity; $279(66.7 \%)$ had severe infection, $78(18.7 \%)$ moderate and $61(14.6 \%)$ had mild infection. Hypertension $(n=195 ; 46.7 \%)$ and diabetes $(n=187 ; 44.7 \%)$ were the most common comorbidities. The most common symptoms at COVID-19 onset were fever $(n=303 ; 72.5 \%)$, cough $(n=278 ; 66.5 \%)$ and dyspnea $(n=256 ; 61.2 \%) .256(61.2 \%)$ patients received ventilation $(36.8 \%$ as invasive and 24.4 as non-invasive).

As detailed in table (1), the severe forms of COVID-19 infection were significantly associated older in age (P. value $<0.001$ ) and had CVD rate in comorbidities (P. value= 0.008$)$, as well as dyspnea (P. value < $0.001)$, headache $(P$. value $=0.026)$ and neurological symptoms $(P$. value $=0.025)$. Malaria infection was 
common in patients with severe infection comparing to those with moderate and mild infection $(23.3 \% \mathrm{vs}$ $14.1 \%$ vs $9.8 \%$; P. value $=0.022$ ). Bilateral crepitation in chest examination was significantly common among the patients with severe disease (P. value< 0.001 ). Ventilation (regardless the types) was initiated in more patients with severe disease than in those with moderate and mild disease $(77.4 \%$ vs $41 \%$ vs 13.1\%; P. value< 0.001 )

Table (1): Clinical characteristics of the study patients, according to disease severity 


\begin{tabular}{|c|c|c|c|c|c|}
\hline & $\begin{array}{c}\text { Total } \\
(\mathrm{N}=418) ; \mathrm{n}(\%)\end{array}$ & $\begin{array}{c}\text { Mild } \\
(\mathrm{N}=61) ; \mathrm{n}(\%)\end{array}$ & $\begin{array}{c}\text { Moderate } \\
(\mathrm{N}=78) \\
\mathrm{n}(\%)\end{array}$ & $\begin{array}{c}\text { Severe } \\
(\mathrm{N}=279) ; \\
\mathrm{n}(\%)\end{array}$ & P. value \\
\hline Age; mean \pm SD & $66.3 \pm 13$ & $57.3 \pm 15$ & $67.7 \pm 11$ & $68 \pm 12$ & $<0.001 * \mathrm{a}$ \\
\hline \multicolumn{6}{|l|}{ Gender } \\
\hline Male & $279(66.7)$ & $46(75.4)$ & $54(69.2)$ & $179(64.2)$ & \multirow{2}{*}{$0.210^{b}$} \\
\hline Female & $139(33.3)$ & $15(24.6)$ & $24(30.8)$ & $100(35.8)$ & \\
\hline \multicolumn{6}{|l|}{ Comorbidities } \\
\hline HTN & 195(46.7) & $22(36.1)$ & $37(47.4)$ & $136(48.7)$ & $0.196^{b}$ \\
\hline Diabetes & $187(44.7)$ & $25(41)$ & $40(51.3)$ & $122(43.7)$ & $0.404^{\mathrm{b}}$ \\
\hline Renal disease & $48(11.5)$ & $11(18)$ & $7(9)$ & $30(10.8)$ & $0.202^{b}$ \\
\hline CVD & $42(10)$ & $2(3.3)$ & $3(3.8)$ & $37(13.3)$ & $0.008 * b$ \\
\hline CPD & $26(6.2)$ & $4(6.6)$ & $7(9)$ & $15(5.4)$ & $0.505^{b}$ \\
\hline Smoking & $19(4.5)$ & $1(1.6)$ & $1(1.3)$ & $17(6.1)$ & $0.120^{b}$ \\
\hline Cerebrovascular & $10(2.4)$ & $0(0)$ & $0(0)$ & $10(3.6)$ & $0.078^{b}$ \\
\hline Malignancy & $8(1.9)$ & $2(3.3)$ & $2(2.6)$ & $4(1.4)$ & $0.570^{b}$ \\
\hline Other & $34(8.1)$ & $6(9.8)$ & $4(5.1)$ & $24(8.6)$ & $0.532^{b}$ \\
\hline \multicolumn{6}{|l|}{ Presentation } \\
\hline Fever & $303(72.5)$ & $44(72.1)$ & $61(78.2)$ & 198(71) & $0.448^{b}$ \\
\hline Cough & $278(66.7)$ & $39(63.9)$ & $51(65.4)$ & $188(67.4)$ & $0.851^{\mathrm{b}}$ \\
\hline Dyspnea & $256(61.2)$ & $46(45.4)$ & $60(76.9)$ & $250(89.6)$ & $<0.001 * b$ \\
\hline Fatigue & 73(17.5) & $10(16.4)$ & $19(24.4)$ & $44(15.8)$ & $0.204^{b}$ \\
\hline Headache & $45(10.8)$ & $6(9.8)$ & $2(2.6)$ & $37(13.3)$ & $0.026 * \mathrm{~b}$ \\
\hline Neurological & $39(9.3)$ & $0(0)$ & $8(10.3)$ & $31(11.1)$ & $0.025 * b$ \\
\hline Vomiting & $22(5.3)$ & $4(6.6)$ & $4(5.1)$ & $14(5)$ & $0.886^{\mathrm{b}}$ \\
\hline LL edema & $16(3.8)$ & $2(3.3)$ & $3(3.8)$ & $11(3.9)$ & $0.970^{b}$ \\
\hline Diarrhea & $15(3.6)$ & $4(6.6)$ & $0(0)$ & $11(3.9)$ & $0.102^{b}$ \\
\hline Sore throat & $14(3.3)$ & $4(6.6)$ & $2(2.6)$ & $8(2.9)$ & $0.319^{b}$ \\
\hline Chest pain & $12(2.9)$ & $2(3.3)$ & $2(2.6)$ & $8(2.9)$ & $0.969^{b}$ \\
\hline Malaria & $82(19.6)$ & $6(9.8)$ & $11(14.1)$ & $65(23.3)$ & $0.022 * b$ \\
\hline \multicolumn{6}{|l|}{$\begin{array}{l}\text { Chest finding } \\
(\mathrm{N}=296)\end{array}$} \\
\hline Clear & $31(10.5)$ & $20(42.6)$ & $4(7.1)$ & $7(3.6)$ & \multirow[t]{3}{*}{$<0.001 * b$} \\
\hline Bilateral crept & $179(60.5)$ & $15(31.9)$ & $36(64.3)$ & $128(66.3)$ & \\
\hline Unilateral crept & $86(29.1)$ & $12(25.5)$ & $16(28.6)$ & $58(30.1)$ & \\
\hline Ventilation (Yes) & $256(61.2)$ & $8(13.1)$ & $32(41)$ & $216(77.4)$ & $<0.001 * \mathrm{~b}$ \\
\hline Non-invasive & 102(24.4) & $4(6.6)$ & $12(15.4)$ & $86(30.8)$ & \multirow[t]{2}{*}{$0.812^{b}$} \\
\hline Invasive & 154(36.8) & $4(6.6)$ & $20(25.6)$ & $130(46.6)$ & \\
\hline $\begin{array}{l}\text { LOS (days); } \\
\text { mean } \pm S D\end{array}$ & $9.1 \pm 5.6$ & $9.9 \pm 4.5$ & $8.7 \pm 4.9$ & $9 \pm 5.9$ & $0.430^{b}$ \\
\hline
\end{tabular}

HTN; hypertension, CPD; chronic pulmonary disease, CVD; cardiovascular disease, LL; lower limb 
On examination, patients with severe disease had significantly greater respiratory rates $(30.6 \pm 9.4 \mathrm{vs}$ $29.2 \pm 7.7$ vs $23.5 \pm 6.3$ breath/min; P. value< 0.001$)$ and pulse rate $(94 \pm 16.5$ vs $90.4 \pm 17.6$ vs $89.5 \pm 12.3$ bpm; $P$. value $=0.041)$ more than those with moderate and mild infection. On hematological parameters, severe infection was correlated with anemia, neutrophilia and lymphcytopenia ( $P$. value< 0.001 ). Concerning to the biochemical tests, patients with severe disease had significantly higher glucose levels (214.8 \pm 94.8 vs $195.6 \pm 76$ vs $148.8 \pm 53.1 \mathrm{mg} / \mathrm{dl} P$. value $<0.001)$, HbA1c levels $(8.6 \pm 2.1$ vs $6.9 \pm 1.6$ vs $5.6 \pm 0.9 \%$; $P$. value $<0.001)$ and creatinine levels $(2 \pm 1.5$ vs $1.8 \pm 1.7$ vs $1.1 \pm 1 \mathrm{mg} / \mathrm{dl} ; \mathrm{P}$. value $=0.002)$ more than those with moderate and mild disease (table 2).

In inflammatory markers, the levels of CRP $(223 \pm 86.3$ vs $137.8 \pm 66$ vs $68.3 \pm 54.4$; P. value $<0.001)$ and ddimer ( $10 \pm 4.2$ vs $6.1 \pm 3.7$ vs $2.1 \pm 1.5$; P. value< 0.001$)$ were elevated in severe infection more than moderate and mild infections (table 2)

Table (2): The examinations and laboratory investigations findings, according to disease severity 


\begin{tabular}{|c|c|c|c|c|c|}
\hline & $\begin{array}{c}\text { Total } \\
(\mathrm{N}=418)\end{array}$ & Mild $(\mathrm{N}=61)$ & $\begin{array}{c}\text { Moderate } \\
(\mathrm{N}=78)\end{array}$ & $\begin{array}{c}\text { Severe } \\
(\mathrm{N}=279)\end{array}$ & P. value \\
\hline \multicolumn{6}{|l|}{ Examination } \\
\hline RR (breath/min) & $29.3 \pm 9$ & $23.5 \pm 6.3$ & $29.2 \pm 7.7$ & $30.6 \pm 9.4$ & $<0.001 * \mathrm{a}$ \\
\hline PR (bpm) & $92.6 \pm 16.2$ & $89.5 \pm 12.3$ & $90.4 \pm 17.6$ & $94 \pm 16.5$ & $0.041 * \mathrm{a}$ \\
\hline $\begin{array}{l}\text { GCS; median } \\
\text { (mini-max) }\end{array}$ & $15(3-15)$ & $15(12-15)$ & $14(6-15)$ & $13(3-15)$ & $<0.001 * \mathrm{a}$ \\
\hline SBP (mm Hg) & $127.8 \pm 23.1$ & $122.6 \pm 17.4$ & $126.2 \pm 27.5$ & $129.4 \pm 22.8$ & $0.093^{a}$ \\
\hline $\mathrm{DBP}(\mathrm{mm} \mathrm{Hg})$ & $77.2 \pm 12.6$ & $76 \pm 13.5$ & $75.6 \pm 10.1$ & $77.8 \pm 13$ & $0.296^{\mathrm{a}}$ \\
\hline SpO2 (\%) & $91.2 \pm 56.8$ & $97.5 \pm 1.2$ & $93.5 \pm 1.9$ & $89.1 \pm 69.5$ & $<0.001 * a$ \\
\hline \multicolumn{6}{|l|}{ Hematology } \\
\hline Hemoglobin (g/dl) & $11.8 \pm 2.2$ & $13.1 \pm 1.5$ & $12 \pm 1.9$ & $11.4 \pm 2.3$ & $<0.001 * \mathrm{a}$ \\
\hline $\begin{array}{l}\text { WBCs } \\
\left(* 10^{\wedge} 3 / \mathrm{Cumm}\right)\end{array}$ & $13.5 \pm 12.3$ & $11.4 \pm 9.1$ & $11.8 \pm 9$ & $14.4 \pm 12$ & $0.114^{\mathrm{a}}$ \\
\hline Neutrophil (\%) & $82 \pm 14$ & $74 \pm 9$ & $77 \pm 14$ & $85 \pm 14$ & $<0.001 * \mathrm{a}$ \\
\hline Lymphocyte (\%) & $13.5 \pm 10$ & $25.3 \pm 12.3$ & $17.7 \pm 9$ & $9.6 \pm 6.2$ & $<0.001 * \mathrm{a}$ \\
\hline Monocyte (\%) & $4 \pm 2.8$ & $3.7 \pm 1.6$ & $4.7 \pm 2.9$ & $3.7 \pm 3$ & $0.060^{a}$ \\
\hline Eosinophil (\%) & $1.1 \pm 0.3$ & $0.8 \pm 0.2$ & $1.1 \pm 0.4$ & $1.2 \pm 0.4$ & $0.645^{\mathrm{a}}$ \\
\hline $\begin{array}{l}\text { Platelets } \\
\left(* 10^{\wedge} 3 / \text { Cumm }\right)\end{array}$ & $268.9 \pm 134.3$ & $292.1 \pm 105.2$ & $270 \pm 108.9$ & $263.3 \pm 146.1$ & $0.320^{a}$ \\
\hline \multicolumn{6}{|l|}{ Biochemistry } \\
\hline Glucose $(\mathrm{mg} / \mathrm{dl})$ & $200.4 \pm 89$ & $148.8 \pm 53.1$ & $195.6 \pm 76$ & $214.8 \pm 94.8$ & $<0.001 * \mathrm{a}$ \\
\hline HbA1c & $7.7 \pm 2$ & $5.6 \pm 0.9$ & $6.9 \pm 1.6$ & $8.6 \pm 2.1$ & $<0.001 * \mathrm{a}$ \\
\hline Creatinine (mg/dl) & $1.8 \pm 1.5$ & $1.1 \pm 1$ & $1.8 \pm 1.7$ & $2 \pm 1.5$ & $0.002 * a$ \\
\hline Sodium $(\mathrm{mmol} / \mathrm{l})$ & $132.6 \pm 6.6$ & $134.4 \pm 4.1$ & $132.5 \pm 6.9$ & $132.2 \pm 7$ & $0.08^{\mathrm{a}}$ \\
\hline $\begin{array}{l}\text { Potassium } \\
(\mathrm{mmol} / \mathrm{l})\end{array}$ & $4.2 \pm 2.6$ & $3.9 \pm 0.4$ & $4 \pm 0.7$ & $4.3 \pm 3.1$ & $0.523^{a}$ \\
\hline \multicolumn{6}{|l|}{ Inflammation } \\
\hline CRP & $180.5 \pm 98.6$ & $68.3 \pm 54.4$ & $137.8 \pm 66$ & $223 \pm 86.3$ & $<0.001 * \mathrm{a}$ \\
\hline D-dimer & $7.8 \pm 4.9$ & $2.1 \pm 1.5$ & $6.1 \pm 3.7$ & $10 \pm 4.2$ & $<0.001 * \mathrm{a}$ \\
\hline
\end{tabular}

RR; respiratory rate, GSC; Glasgow coma score, SBP; systolic blood pressure, DBP; diastolic blood pressure, SpO2; oxygen saturation, WBCs; white blood cells, HbA1c; glycosylated hemoglobin; CRP C-reactive protein *significant $(<0.05),{ }^{a}$ ANOVA test, B Chisquare test

Table (3) shows the radiologic findings on admission. Of $160 \mathrm{CT}$ scans that were performed at the time of admission, $97(23.2 \%)$ exhibited ground-glass opacity, 38(9.1\%) bilateral consolidation $(51.8 \%)$ and $21(5 \%)$ showed diffused consolidation. In chest $x$-ray, $2.3 \%(n=10)$ of the patients had bilateral consolidation and $0.2 \%(n=1)$ had Mediastina patchy opacity. ECG abnormalities were encountered in 42 patients and mainly as LAD in 13(3.1\%) patients, LBBB in 10(2.3\%) and T-wave abnormalities in also $10(2.3 \%)$ patients 
Table (3): Radiologic findings of the study patients, according to disease severity

\begin{tabular}{|c|c|c|c|c|c|}
\hline & $\begin{array}{c}\text { Total } \\
(\mathrm{N}=418) ; \mathrm{n}(\%)\end{array}$ & $\begin{array}{c}\text { Mild } \\
(\mathrm{N}=61) ; \mathrm{n}(\%)\end{array}$ & $\begin{array}{c}\text { Moderate } \\
(\mathrm{N}=78) ; \\
\mathrm{n}(\%)\end{array}$ & $\begin{array}{c}\text { Severe } \\
(N=279) \\
n(\%)\end{array}$ & $\begin{array}{c}\mathrm{P} . \\
\text { value }\end{array}$ \\
\hline \multicolumn{6}{|l|}{$\mathrm{CT}(\mathrm{N}=160)$} \\
\hline Ground gross & 97(23.2) & $13(72.2)$ & $18(58.1)$ & $66(59.5)$ & \multirow{3}{*}{$0.675^{b}$} \\
\hline Bilateral consolidation & $38(9.1)$ & $2(11.1)$ & $9(29)$ & $27(24.3)$ & \\
\hline Diffused consolidation & $21(5)$ & $3(16.7)$ & $4(12.9)$ & $14(12.6)$ & \\
\hline \multicolumn{6}{|l|}{ CXR $(\mathrm{N}=11)$} \\
\hline Bilateral consolidation & $10(2.3)$ & $0(0)$ & $2(66.7)$ & $8(100)$ & \multirow[t]{2}{*}{$0.273^{b}$} \\
\hline $\begin{array}{l}\text { Mediastina patchy } \\
\text { opacity }\end{array}$ & $1(0.2)$ & $0(0)$ & $1(33.3)$ & $0(0)$ & \\
\hline \multicolumn{6}{|l|}{ ECG $(\mathrm{N}=42)$} \\
\hline LAD & 13(3.1) & $0(0)$ & $1(1.3)$ & $10(3.6)$ & \multirow[t]{9}{*}{$0.853^{b}$} \\
\hline $\mathrm{LBBB}$ & $10(2.3)$ & $2(3.3)$ & $2(2.6)$ & $6(2.2)$ & \\
\hline T-wave & $10(2.3)$ & $0(0)$ & $4(5.2)$ & $6(2.2)$ & \\
\hline Q-wave & $2(0.4)$ & $0(0)$ & $0(0)$ & $2(0.7)$ & \\
\hline $\mathrm{RBBB}$ & $2(0.4)$ & $0(0)$ & $0(0)$ & $2(0.7)$ & \\
\hline $\mathrm{LVH}$ & $2(0.4)$ & $0(0)$ & $0(0)$ & $2(0.7)$ & \\
\hline STE & $1(0.2)$ & $0(0)$ & $0(0)$ & $1(0.4)$ & \\
\hline STD & $1(0.2)$ & $0(0)$ & $0(0)$ & $1(0.4)$ & \\
\hline Tachycardia & $1(0.2)$ & $0(0)$ & $0(0)$ & $1(0.4)$ & \\
\hline
\end{tabular}

CT; computed tomography, CXR; chest x-ray, ECG; electrocardiography, LBBB; left bundle branch block, RBBB; right bundle branch block, LVH; left ventricular hypertrophy, STE; ST-elevation, STD; ST-depression

\section{b Chi-square test}

As illustrated in figure (1), the overall mortality rate was $35.4 \%(n=148)$. The morality rate was $42.3 \%$ $(n=118)$ among patients with severe disease, $34.6 \%(n=27)$ among those with moderate and $4.9 \%(n=3)$ among patients with mild disease (P. value $<0.001)$

\section{Discussion}

We found 16 variables that were associated with severe COVID-19 disease. In our study we describe the potential risk factors for COVID-19 disease progression in Sudanese patients. Given the severity of this global public health emergency, we believe that this report is important for understanding the clinical characteristics of COVID-19 infection and identifying the risk factors associated with the severity of the disease. In our study we included 418 confirmed COVID-19 patients with a median age of $66.3 \pm 13$ years with an overall mortality rate of $35.4 \%(n=148)$. The predominate gender was male gender. With regard to the comorbidities, Hypertension and Diabetes were the most common comorbidities. The most common symptoms at COVID-19 onset were fever, cough and dyspnea. We found that mortality rate 
was high among patients with severe disease. As shown in this study, we found 16 variables that were associated with COVID-19 severity. We found older patients to be significantly associated with severe disease. This is in alignment with a global systematic review and meta-analysis were old age was identified as a risk factor for severe disease. This might be due to comorbidities of age, as well as the less functional immune system due to ageing. In our study, patients that had CVD rate in comorbidities were significantly associated with severe disease. This is similar to a meta-analysis were COVID-19 patients who suffered from CVD tended to have more adverse outcomes. We found dyspnea to also be significantly associated with severe disease (11). This is in alignment with a national study done in South Korea(12) were dyspnea increased the risk of severe COVID-19. We found headache to be significantly associated with severe disease. In contrast to a study where having no headache was associated with the progression to severity stages of COVID-19 disease (12). No specific mechanisms have been reported on the mechanism of headache in COVID-19 patients. However, a proposal suggests that one of the main pathomechanism of headache in these patients is the activation of trigeminal nerve ending in the periphery followed by the sensitization of various sites in the brain(13). In our study, neurological symptoms were significantly associated with severe disease. This is in line with a study that addressed neurological manifestations as an associated factor with severe COVID-19 mortality (14). On examination, our patients with severe disease had significantly greater respiratory rates and pulse rate than those with moderate and mild infection. This is in alignment with a study were patients with high pulse and respiratory rates were listed as clinical characteristics of severe COVID-19 disease (15). Also we found severe infection to be significantly associated with anemia, similar to studies where lower levels of hemoglobin were associated with severe COVID-19 disease (16)(17). In our study, we found malarial infection on presentation to be associated with severe disease. This is in line with a study where it states that co-infection can reflect the severity and adverse outcomes compared to COVID-19 alone (18). We found neutrophilia to be significantly associated with the severe form of the disease, similar to findings in a study done on Neutrophils in COVID-19 stating the raised levels of neutrophils found in severe COVID19 disease (19). We also found lymphcytopenia to be significantly associated with severe disease. This is similar to a study where lymphopenia were more commonly seen in severe COVID-19 illness. We found higher glucose levels and $\mathrm{HbA1c}$ levels to be significantly associated with severe disease (15). This is similar to a study where both higher glucose levels and $\mathrm{HbA} 1 \mathrm{c}$ levels were significantly associated with severity of the COVID-19 disease (20). We found creatinine levels to be significantly associated with sever disease. This is in line with a study were creatinine levels were significantly associated with severe disease. When it comes to the inflammatory markers, the levels of CRP and d-dimer were significantly elevated in severe infection more than moderate and mild infections (21). This is similar to studies were both markers were associated with sever disease (21)(22).

Identifying these risk factors is very crucial and can alert careful observation and early intervention and identify the severity of illness as early as possible also to improve the management of patients at risk and prevent disease progression, reduce mortality as well as to guide the implementation of public health measures to limit the impact of COVID-19 on vulnerable populations. Multicenter studies will have better 
help to further determine the clinical characteristics and analysis of risk factors for disease progression in Sudan

\section{Strengths and limitations:}

Our study has a number of strengths. This is the first retrospective cohort study done in Sudan concerning this topic. We were very selective with inclusion and exclusion criteria. This is the first study that's represents the picture and progression of COVID-19 among Sudanese patients. It magnified the role of specific laboratory markers in determination of final outcomes. This study represents a data base for any future studies concerning with COVID-19 in the region.

Our study has some limitations. First, this study was a retrospective cohort study, without the validation of prospective studies. Secondly, when we collected data, a large number of patients are excluded because who have their files incomplete and could not be reached by phone, which may lead to potential selection bias. Despite the importance of radiography in the identification and diagnosis of COVID-19, not all patients underwent a chest imaging (chest CT scans and chest x-ray) examination at the time of admission. Also we could not access major isolation centers which are located in Khartoum state.

\section{Conclusion}

This study included 418 patients confirmed COVID-19 cases with a median age of $66.3 \pm 13$ years. The overall mortality rate was $35.4 \%$. The mortality rate was high among patients with severe disease. As shown in this study, 16 variables were found to be associated with COVID-19 severity. Identifying these risk factors is crucial for early identification of the severe illness to improve the management of patients at risk and prevent disease progression. Multicenter studies will have better help to further determine the clinical characteristics and analysis of risk factors for disease progression in Sudan.

\section{Declarations}

\section{Ethics approval and consent to participate:}

Ethical approval was obtained from each center ethical committee. Both verbal and written consents to publish this information was obtained from the patients.

\section{Consent to publish:}

Consent for publication was obtained from all patients and authors.

\section{Availability of data and materials:}

The datasets used and $\backslash$ or analyzed during the current study are available from corresponding author on reasonable request. 


\section{Competing interests:}

The authors have no conflict of interest to declare.

\section{Funding:}

The authors received no funding for this work.

\section{Acknowledgment:}

Not applicable.

\section{References}

1.Chang MC, Park D: How should rehabilitative departments of hospitals prepare for coronavirus disease 2019? Am J Phys Med Rehabil 2020.

2.Kucharski AJ, Russell TW, Diamond C, Liu Y, Edmunds J, Funk S, Eggo RM, Centre for Mathematical Modelling of infectious diseases C-wg: early dynamics of transmission and control of COVID-19: a mathematical modelling study. Lancet Infect Dis 2020.

3.Chang MC, Seo WS, Park D, Hur J. Analysis of SARS-CoV-2 Screening Clinic (Including Drive-Through System) Data at a Single University Hospital in South Korea from 27 January 2020 to 31 March 2020 during the COVID-19 Outbreak. Healthcare (Basel). 2020;8(2).

4. CDC daily update-https://africacdc.org/covid-19/

5. https://www.ecdc.europa.eu/en/geographical-distribution-2019-ncov-cases

6. Ayman Ahmed, Nouh Saad Mohamed, Sarah Misbah EL-Sadig. COVID-19 in Sudan. the Journal of Infection in Developing Countries • March 2021.

7.Xie J, Tong Z, Guan X, Du B, Qiu H. Clinical Characteristics of Patients Who Died of Coronavirus Disease 2019 in China. JAMA Netw Open. 2020;3:e205619.

8.Li Zou.Clinical Characteristics and Risk Factors for Disease Severity and Death in Patients With Coronavirus Disease 2019 in Wuhan, China. Front. Med., 13 August

2020 https://doi.org/10.3389/fmed.2020.00532

9. Y. Xing, H. Wang, X.-H. Yao, Y. Li, J.-T. Huang, J. Tang, S. Zhu, Y.-Q. Liu, J. Xiao Analysis of factors for disease progression in 61 patients with COVID-19 in Xiaogan, Hubei, China

10. Lee, S.-G.; Park, G.U.; Moon, Y.R.; Sung, K. Clinical Characteristics and Risk Factors for Fatality and Severity in Patients with Coronavirus Disease in Korea: A Nationwide Population-Based Retrospective 
Study Using the Korean Health Insurance Review and Assessment Service (HIRA) Database. Int. J. Environ. Res. Public Health 2020, 17, 8559. https://doi.org/10.3390/ijerph17228559

11. Xu J, Xiao W, Liang X, Shi L, Zhang P, Wang Y, et al. A meta-analysis on the risk factors adjusted association between cardiovascular disease and COVID-19 severity. BMC Public Health. 2021;21(1).

12. Kim SR, Nam SH, Kim YR. Risk factors on the progression to clinical outcomes of covid-19 patients in south korea: Using national data. Int J Environ Res Public Health. 2020;17(23):1-9.

13. Mutiawati E, Syahrul S, Fahriani M, Fajar JK, Mamada SS, Maliga HA, et al. Global prevalence and pathogenesis of headache in COVID-19: A systematic review and meta-analysis. F1000Research. 2021;9:1-21.

14. Carlos CR, Gerardo MM, Jaime OG, Group N. NEUROLOGY. 2021;1.

15. Zhou F, Yu T, Du R, Fan G, Liu Y, Liu Z, et al. Clinical course and risk factors for mortality of adult inpatients with COVID-19 in Wuhan, China: a retrospective cohort study. Lancet. 2020;395(10229):105462.

16. Mudatsir M, Fajar JK, Wulandari L, Soegiarto G, Ilmawan M, Purnamasari Y, et al. Predictors of COVID19 severity: a systematic review and meta-analysis [ version 1; peer review: 2 approved]. Clin Infect Dis. 2020;71(16):2199-206.

17. Gesesew HA, Koye DiN, Fetene DM, Woldegiorgis M, Kinfu Y, Geleto AB, et al. Risk factors for COVID19 infection, disease severity and related deaths in Africa: A systematic review. BMJ Open. 2021;11(2):110.

18. Muhammad Y, Aminu YK, Ahmad AE, lliya S, Muhd N, Yahaya M, et al. PGF2a ) in COVID -19 subjects co-infected with malaria. 2020;37(78).

19. Reusch N, De Domenico E, Bonaguro L, Schulte-Schrepping J, Baßler K, Schultze JL, et al. Neutrophils in COVID-19. Front Immunol. 2021;12(March):1-9.

20. Logette E, Lorin C, Favreau C, Oshurko E, Coggan JS, Casalegno F, et al. A Machine-Generated View of the Role of Blood Glucose Levels in the Severity of COVID-19. Front Public Heal. 2021;9(July):1-53.

21. Izcovich A, Ragusa MA, Tortosa F, Marzio MAL, Agnoletti C, Bengolea A, et al. Prognostic factors for severity and mortality in patients infected with COVID-19: A systematic review. PLoS One. 2020;15(11 November):1-30.

22. Huang Y, Lyu X, Li D, Wang L, Wang Y, Zou W, et al. A cohort study of 676 patients indicates Ddimer is a critical risk factor for the mortality of COVID-19. PLoS One [Internet]. 2020;15(11 November):1-11. Available from: http://dx.doi.org/10.1371/journal.pone.0242045 
Figures

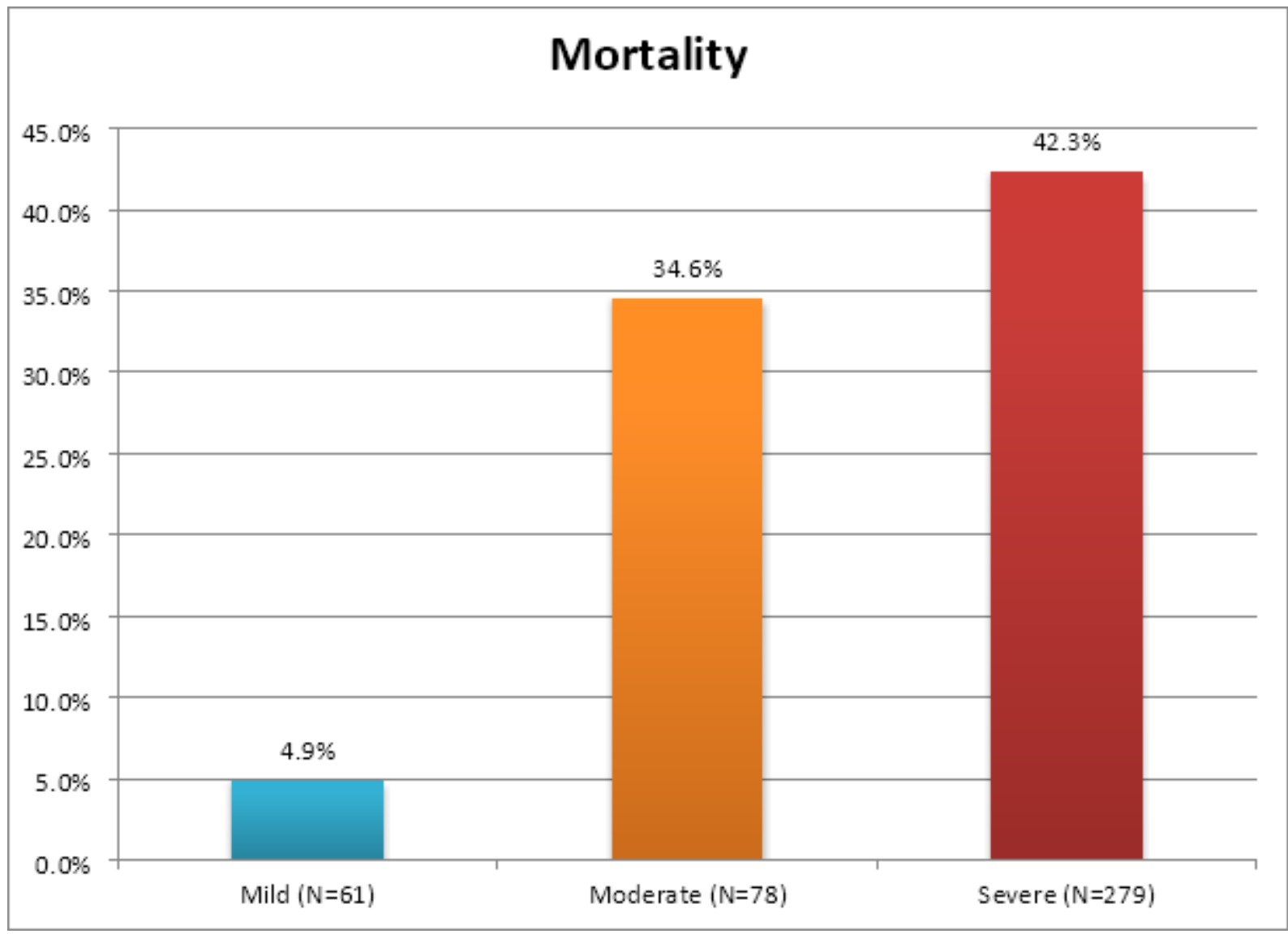

Figure 1

Distribution of mortality according to disease severity 